\title{
MENINGKATKAN PEMAHAMAN KONSEP FISIKA MELALUI METODE DEMONSTRASI PADA PEMBELAJARAN FISIKA SISWA KELAS $X$ DI SMA NEGERI 1 BAUBAU
}

\author{
Arianto Atjo \\ Dinas Pendidikan, Pemuda, dan Olahraga Kota Baubau, SMA Negeri 1 Baubau, \\ Jl. Moh. Husni Tamrin No. .... Baubau \\ E-mail:arianto.atjo@gmail.com
}

\begin{abstract}
Abstrak
Tujuan penelitian ini adalah untuk mengetahui efektivitas penggunaan metode demonstrasi pada pembelajaran Fisika siswa kelas X di SMA Negeri 1 Baubau Penelitian ini adalah penelitian tindakan kelas. Penelitian tindakan kelas ini dilaksanakan di SMA Negeri 1 Baubau pada siswa kelas X-1 s.d. 8. Hasil penelitian meunjukkan bahwa hasil belajar Fisika siswa meningkat setelah mengikuti kegiatan belajar mengajar yang menggunakan metode demonstrasi. Adapun peningkatan prestasi dari siklus I sampai siklus II sebesar $23,38 \%$.
\end{abstract}

Kata kunci: media pembelajaran, demonstrasi.

\begin{abstract}
The purpose of this study was to determine the effectiveness of the use of methods of demonstration in physics learning class X in SMA Negeri 1 Baubau This research is a class act. This classroom action research conducted in SMA Negeri 1 Baubau in class X-1 until 8. The results of the study reveals that a physics student learning outcomes improved after following the teaching and learning activities using the method of demonstration. The achievement of the first cycle to the second cycle of $23.38 \%$.
\end{abstract}

Keywords: instructional media, demonstrations. 


\section{SANG PENCERAH}

Volume 3, Nomor 2, Agustus 2017, Hlm. 11-18

\section{Arianto Atjo: Meningkatkan Pemahaman Konsep Fisika ...}

\section{Pendahuluan}

Salah satu penyebab rendahnya hasil belajar fisika siswa di SMA Negeri 1 Baubau adalah kesulitan memahami konsep-konsep fisika. Kalau dirunut peluang terbesar pokok permasalahan ini adalah bagaimana seorang guru mampu menciptakan proses belajar mengajar fisika yang kreatif, aktif dan menyenangkan. Untuk menciptakan proses belajar mengajar tersebut, guru sebagai pengelola pembelajaran diharap mampu memilih suatu metode secara kreatif dan kemudian inovatif dalam menyampaikanya, serta berani melakukan otokritik bila tujuan yang dicapai tidak sesuai.

Satu metode yang saat ini dikembangkan sebagai solosi terhadap kemerosotan prestasi belajar fisika adalah demonstrasi. Kelebihan metode demonstrasi adalah mampu membuat porses pembelajaran lebih jelas dan kongkrit, sehingga siswa lebih aktif mengamati serta cepat menyesuaikan antara teori dan kenyataan. Yang dimaksud metode demonstrasi adalah salah satu cara mengajar, di mana guru melakukan suatu percobaan tentang sesuatu hal, mengamati prosesnya serta menuliskan hasil percobaannya, kemudian hasil pengamatan itu disampaikan ke kelas dan dievaluasi oleh guru. Agar pelaksanaan metode demonstrasi berlangsung efektif dan efisien, guru harus menetapkan dan mendesain langkah-langkah demonstrasi yang efektif, sehinga tujuan pembelajaran yang berupa peningkatan hasil belajar siswa dapat tercapai. Berdasarkan deskripsi di atas, fokus penelitian ini adalah bagaimana meningkatkan pemahaman konsep fisika melalui metode demonstrasi pada pembelajaran Fisika siswa kelas $X$ semester ganjil tahun pelajaran 2013/2014 di SMA Negeri 1 Baubau?

Tujuan penelitian ini adalah untuk mengetahui efektivitas penggunaan metode demonstrasi pada pembelajaran Fisika siswa kelas $X$ semester ganjil tahun pelajaran 2013/2014 di SMA Negeri 1 Baubau.

\section{Metode Penelitian}

Penelitian tindakan kelas ini dilaksanakan di SMA Negeri 1 Baubau. Subjek penelitiannya adalah siswa kelas X-1 s.d. 8 semester ganjil tahun pelajaran 2016/2017. Penelitian tindakan kelas ini dilakukan dalam 2 siklus dengan tahapan-tahapan masing-masing siklus, yaitu perencanaan, pelaksanaan, pengamatan, dan refleksi.

Instrumen yang digunakan dalam penelitian ini adalah (1) Perangkat pembelajaran yang terdiri dari program tahunan, program semester dan RPP; (2) Lembar observasi; (3) Lember kuesioner siswa; (4) Lembar pengamatan guru pada proses demonstrasi; dan (5) alat evaluasi.

\section{Pembahasan}

\section{Deskripsi Hasil Penelitian Siklus I}

Pada siklus tindakan penelitian, guru melaksanakan tindakan seperti yang direncanakan dan diamati oleh kolaborator. Diskripsi aktifitas siswa yang diperoleh sebagai refleksi terhadap tindakan yang dilakukan guru pada siklus ini dapat dilihat dalam tabel dibawah ini.

Tabel 1. Kegiatan Siswa Saat KBM Berlangsung pada Siklus I 


\section{SANG PENCERAH}

Volume 3, Nomor 2, Agustus 2017, Hlm. 11-18

Arianto Atjo: Meningkatkan Pemahaman Konsep Fisika ...

\begin{tabular}{|c|c|c|}
\hline Kegiatan & Kategori & Diskripsi \\
\hline \multicolumn{3}{|l|}{ Pendahuluan } \\
\hline $\begin{array}{l}\text { 1. Kelas tertip dan } \\
\text { tenang }\end{array}$ & $\mathrm{C}$ & Cukup \\
\hline $\begin{array}{l}\text { 2. Memperhatikan } \\
\text { penjelasan guru }\end{array}$ & C & Cukup \\
\hline $\begin{array}{l}\text { 3. Mencatat penjelasan } \\
\text { guru }\end{array}$ & $\mathrm{C}$ & Cukup \\
\hline \multicolumn{3}{|l|}{ Kegiatan inti } \\
\hline $\begin{array}{l}\text { 1. Sebagian siswa } \\
\text { merangkai alat }\end{array}$ & $\mathrm{C}$ & Cukup \\
\hline $\begin{array}{l}\text { 2. Mengamati yang } \\
\text { terjadi }\end{array}$ & $\mathrm{C}$ & Cukup \\
\hline $\begin{array}{l}\text { 3. Mencatat hasil } \\
\text { pengamatan }\end{array}$ & B & Baik \\
\hline $\begin{array}{l}\text { 4. Melaksanakan } \\
\text { diskusi }\end{array}$ & B & Baik \\
\hline $\begin{array}{l}\text { 5. Membuat } \\
\text { mencatat } \\
\text { kesimpulan }\end{array}$ & C & Cukup \\
\hline \multicolumn{3}{|l|}{ Penutup } \\
\hline $\begin{array}{l}\text { 1. Menjawab } \\
\text { pertanyaan guru }\end{array}$ & $\mathrm{C}$ & Cukup \\
\hline 2. Mencatat contoh & $\mathrm{C}$ & Cukup \\
\hline $\begin{array}{l}\text { 3. Mencatat pekerjaan } \\
\text { rumah }\end{array}$ & B & Baik \\
\hline
\end{tabular}

Hasil dari catatan pada siklus ini adalah beberapa siswa menjawab pertanyaan guru secara bersama, siswa tidak cepat tanggap terhadap pertanyaan guru, dan siswa kurang dapat mencari contoh permasalahan dalam kehidupan sehari-hari.

\section{Refleksi Siklus I}

Dari pelaksanaan siklus I didapatkan hasil bahwa langkahlangkah yang dilakukan guru dalam melaksanakan metode demonstrasi sudah dilaksanakan sesuai rencana, tetapi kegiatan siswa saat Kegiatan Belajar Mengajar (KBM) justru sebaliknya berlangsung kurang baik, khususnya saat pendahuluan (prasyarat dan motivasi), kegiatan inti (merangkai alat dan pengamatan demonstrasi). Sedangkan pada bagian penutup kekurangan terletak di evaluasi dan pengembangan. Peningkatan ketuntasan hasil belajar dalam siklus ini juga masih rendah, bila dibandingkan dengan hasil belajar sebelum pelaksanaan metode demonstrasi, yaitu sebesar 9,63\% (dari $53,5 \%$ menjadi $63,13 \%$ ). Hal ini dapat disebabkan oleh berbagai factor, yaitu sebagian siswa tidak sepenuhnya dapat konsentrasi, waktu demonstrasi guru kurang memperhatikan keaktifan siswa, dan criteria tiap langkah yang ditempuh guru kurang sesuai dengan proses belajar mengajar. Agar diperoleh hasil yang optimal, guru harus bias membawa siswa untuk lebih aktif dalam KBM.

Banyaknya terdapat kekurangan pada siklus I, maka siklus II dilaksanakan dengan memperbaiki kriteria tiap langkah yang memiliki kekurangan tersebut. Dengan demikian guru dapat mencipkan suasana KBM yang optimal, sehingga terjadi interaksi antara siswa dengan sumber pembelajaran. Adapun langkah-langkah yang diperbaiki perhatikan tabel berikut.

Tabel 2. Perbaikan Langkah-Langkah Pelaksanaan Metode Demonstrasi

\begin{tabular}{|c|c|}
\hline SIKLUS I & SIKLUS II \\
\hline Pendahuluan & Pendahu \\
\hline 1. Prasyarat pengetahuan & luan \\
\hline a. Pertanyaan guru tidak & 1. Prasyarat \\
\hline $\begin{array}{l}\text { relevan }(\lambda) \text {. } \\
\text { b. Menanyakan }\end{array}$ & $\begin{array}{l}\text { pengetahuan } \\
\text { a. Menanyakan }\end{array}$ \\
\hline $\begin{array}{l}\text { pengetahuan yang } \\
\text { relevan. }\end{array}$ & $\begin{array}{l}\text { pengetahuan } \\
\text { yang relevan }\end{array}$ \\
\hline c. Merespon jawaban. & b. Sedikit \\
\hline 2. Motivasi & mengulas \\
\hline $\begin{array}{l}\text { a. Menanyakan kejadian } \\
\text { yang relevan. }\end{array}$ & $\begin{array}{l}\text { materi yang } \\
\text { terkait }(+)\end{array}$ \\
\hline $\begin{array}{l}\text { b. Memberi penjelasan } \\
\text { pentinya materi. }\end{array}$ & $\begin{array}{l}\text { c. Merespon } \\
\text { jawaban }\end{array}$ \\
\hline & 2. Motifasi \\
\hline Kegiatan Inti & a. Menanyakan \\
\hline $\begin{array}{l}\text { 1.Merangkai Alat } \\
\text { a. Menjelaskan gambar } \\
\text { jangka sorong }\end{array}$ & $\begin{array}{l}\text { kejadian yang } \\
\text { relevan } \\
\text { b. Mendiskripsi }\end{array}$ \\
\hline $\begin{array}{l}\text { b. Menjelaskan } \\
\text { memakai }\end{array}$ & $\begin{array}{l}\text { kan peristiwa } \\
\text { yg relevan }(+)\end{array}$ \\
\hline $\begin{array}{l}\text { 2. Membimbing Pengamatan } \\
\text { a. Menjelaskan hal yang } \\
\text { diukur. }\end{array}$ & $\begin{array}{l}\text { c. Menaggapi } \\
\text { jawaban siswa } \\
(+)\end{array}$ \\
\hline
\end{tabular}




\section{SANG PENCERAH}

Volume 3, Nomor 2, Agustus 2017, Hlm. 11-18

Arianto Atjo: Meningkatkan Pemahaman Konsep Fisika ...

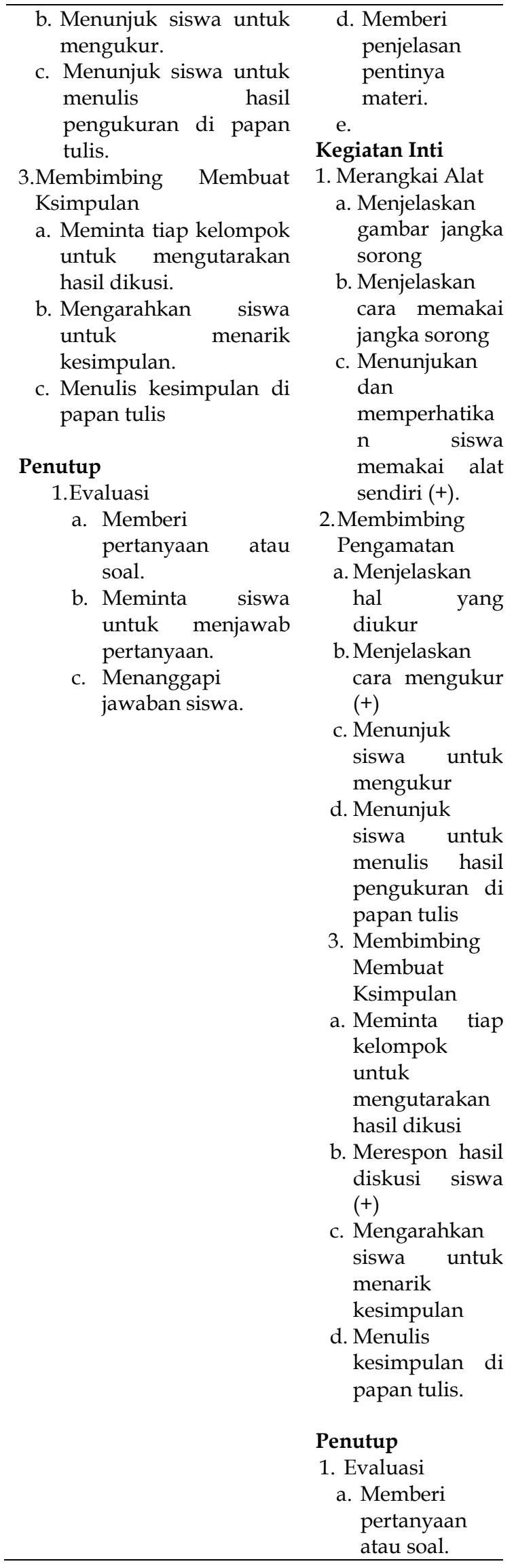

\begin{tabular}{|c|c|}
\hline & $\begin{array}{l}\text { b. Meminta } \\
\text { siswa untuk } \\
\text { menjawab } \\
\text { pertanyaan. } \\
\text { c. Mendiskripsik } \\
\text { an pertanyaan } \\
(+) \text {. } \\
\text { d. Menanggapi } \\
\text { jawaban siswa }\end{array}$ \\
\hline $\begin{array}{l}\text { Keterangan : } \\
\text { X : Tindakan } \\
\text { siklus II } \\
+: \text { Tindakan } \\
\\
\text { siklus II }\end{array}$ & $\begin{array}{l}\text { tilangkan pada } \\
\text { unculkan pada }\end{array}$ \\
\hline
\end{tabular}

Deskripsi Hasil Penelitian Siklus I

Rencana tindakan pada siklus ini dapat dilihat pada tabel II di atas. Diskripsi aktifitas siswa yang dieroleh sebagai akibat dari pelaksanaan tindakan di atas dapat dilihat pada table berikut.

Tabel 3. Kegiatan Siswa Saat KBM Berlangsung pada siklus II

\begin{tabular}{|c|c|c|}
\hline Kegiatan & Kategori & Diskripsi \\
\hline \multicolumn{3}{|l|}{ Pendahuluan } \\
\hline $\begin{array}{l}\text { 1. Kelas tertip dan } \\
\text { tenang. }\end{array}$ & B & Baik \\
\hline $\begin{array}{l}\text { 2. Memperhatikan } \\
\text { penjelasan guru. }\end{array}$ & B & Baik \\
\hline $\begin{array}{l}\text { 3. Mencatat } \\
\text { penjelasan guru. }\end{array}$ & B & Baik \\
\hline \multicolumn{3}{|l|}{ Kegiatan inti } \\
\hline $\begin{array}{l}\text { 1. Sebagian siswa } \\
\text { merangkai alat. }\end{array}$ & B & Baik \\
\hline $\begin{array}{l}\text { 2. Mengamati yang } \\
\text { terjadi. }\end{array}$ & B & Baik \\
\hline $\begin{array}{l}\text { 3. Mencatat hasil } \\
\text { pengamatan. }\end{array}$ & B & Baik \\
\hline $\begin{array}{l}\text { 4. Melaksanakan } \\
\text { diskusi. }\end{array}$ & B & Baik \\
\hline $\begin{array}{l}\text { 5. Membuat dan } \\
\text { mencatat } \\
\text { kesimpulan. }\end{array}$ & B & Baik \\
\hline \multicolumn{3}{|l|}{ Penutup } \\
\hline $\begin{array}{l}\text { 1. Menjawab } \\
\text { pertanyaan guru. }\end{array}$ & B & Baik \\
\hline 2. Mencatat contoh. & B & Baik \\
\hline $\begin{array}{l}\text { 3. Mencatat pekerjaan } \\
\text { rumah. }\end{array}$ & B & Baik \\
\hline
\end{tabular}




\section{SANG PENCERAH}

Volume 3, Nomor 2, Agustus 2017, Hlm. 11-18

\section{Arianto Atjo: Meningkatkan Pemahaman Konsep Fisika ...}

Adapun ketuntasan hasil belajar fisika siswa yang diperoleh dalam siklus ini adalah $76.88 \%$.

\section{Refleksi Siklus II}

Aktivitas dan ketuntasan belajar siswa pada siklus ini mengalami peningkatan bila dibandingkan dengan siklus I. Adapun peningkatan ketuntasan belajar siswa pada siklus ini sebesar 13,75\% (dari 63,13\% menjadi $76,88 \%)$.

Pada siklus II, siswa lebih aktif dalam mengikuti KBM bila dibandingkan dengan siklus I. Peningkatan keaktifan siswa ini dikarenakan tindakan guru lebih aktif dan kreatif dalam mengarahkan dan membimbing siswa. Sebagai contoh, saat pendahuluan ketika guru memberikan pertanyaan dan siswa masih pasif, maka guru menguraikan lagi pertanyaan yang diajukan sehingga siswa mampu menjawab. Pada kegiatan ini, guru lebih banyak memberi kesempatan kepada siswa untuk menggunakan alat sendiri. Guru hanya menunjuk dan memperhatikan saja. Untuk pengamatan hasil, guru menjelaskan cara mengamati sedangkan siswa sebagai pengamat. Dengan tindakan ini, siswa menjadi aktip dan mengeti apa yang harus dilakukan, sehingga konsep yang akan ditanamkan, lebih mudah ditangkap dan dipahami siswa. Demikian juga saat pelaksanaan diskusi, guru dengan aktif membimbing dan mengatur jalanya diskusi dengan baik dan aktif.

Pada saat evaluasi (tes lisan), bila siswa belum mampu menjawab, maka guru menguraikan pertanyaanya ke tingkat yang lebih rendah. Tindakan ini dimaksudkan untuk memotivasi siswa agar mau menjawab pertanyaan guru dan mampu memberikan contoh penerapan konsep dalam kehidupan sehari-hari. Secara keseluruhan langkah-langkah metode demonstrasi yang efektif hasil perbaikan dari siklus I ke siklus II sebagai berikut.

\section{Pendahuluan}

Guru menertibkan suasana kelas, yaitu (a) memperhatikan siswa saat memasuki labolatorium, (b) mengatur posisi duduk siswa, (c) menenangkan siswa sebelum mulai mengajar, (d) mengabsen siswa. Guru memberikan prasyarat pengetahuan, yaitu (a) guru menanyakan pengetahuan yang telah dimiliki siswa yang relevan dengan materi yang akan dibahas, (b) guru sedikit mengulas materi yang terkait dengan pertanyaan prasyarat, (c) guru merespon jawaban siswa.

Guru memberikan motivasi, yaitu (a) guru menanyakan kejadian sehari-hari yang berhubungan dengan materi yang akan dibahas, (b) guru mendiskripsikan peristiwa sehari-hari yang berkaitan dengan pertanyaan motivasi, (c) guru menanggapi jawaban siswa, (d) guru memberi penjelasan tentang pentingnya materi dalam kehidupan sehari-hari. Guru menyampaikan tujuan pembelajaran, yaitu (a) guru menulis tujuan pembelajaran, (b) guru menjelaskan tujuan pembelajaran. Guru menyiapan alat untuk demonstrasi, yaitu (a) mengeluarkan alat yang akan dipakai dari ruang persiapan, (b) menempatkan alat ditempat yang mudah diamati oleh siswa.

Guru menjelaskan kegunaan alat, yaitu (a) memperkenalkan nama alat, (b) memperjelaskan kegunaan alat. Guru menjelaskan cara kerja alat, yaitu (a) menjelaskan cara menggunakan alat, (b) menjelaskan cara membaca skala 


\section{SANG PENCERAH}

Volume 3, Nomor 2, Agustus 2017, Hlm. 11-18

\section{Arianto Atjo: Meningkatkan Pemahaman Konsep Fisika ...}

pada alat. Guru menjelaskan tehnik keselamatan kerja, yaitu (a) menjelaskan keselamatan alat, (b) menjaga alat agar tidak rusak, (c) menginformasikan tentang keselamatan siswa.

\section{Kegiatan Inti/Pokok}

Guru mengukur menggunakan jangka sorong dengan melibatkan siswa : (a) guru menjelaskan kegunaan jangka sorong; (b) guru menjelaskan skala pada jangka sorong; (c) guru nengukur benda atau dengan melibatkan siswa; (d) guru menunjuk. Guru membimbing siswa untuk mencatat hasil pengamatan : (a) menjelaskan hasil pengukuran; (b) menyuruh siswa untuk memasukan data hasil pengukuran pada LKS. Guru memimpin diskusi isian LKS: (a) membentuk kelompok kecil; (b) menjelaskan teknis diskusi, (c) guru membimbing siswa secara bergantian tiap kelompok; (d) guru menertipkan diskusi siswa. Guru membimbing siswa untuk kesimpulan: (a) meminta tiap kelompok untuk mengutarakan hasil diskusi; (b) guru menanggapi hasil diskusi tiap kelompok; (c) guru mengarahkan siswa untuk menarik kesimpulan; (d) guru menulis kesimpulan di papan tulis.

\section{Penutup}

Guru melaksanakan evaluasi test lisan atau test tertulis: (a) guru memberikan pertanyaan atau soal, (b) guru meminta siswa untuk menjawab, (c) guru mendiskripsikan pertanyaan agar siswa siswa mampu menjawab, : (d) guru menangggapi jawaban lisan.

Guru memberikan contoh dalam kehidupan sehari-hari yang sesuai dengan konsep: (a) memberikan contoh penerapan konsep fisika dalam kehidupan sehari-hari, (b) menyuruh siswa mencari contoh penerapan konsep fisika dalam kehidupan sehari-hari, (c) guru menunjukan adanya keterkaitan fisika dengan permasalahanya yang ditemui dalam kehidupan seharihari. Guru meberikan pekerjaan rumah: (a) guru memberikan soal, (b) guru menyuruh siswa mencatat soal, (c) guru menyarankan agar PR dikerjakan sendiri.

Tabel 4. Perbandingan Pemahaman Konsep Fisika

\begin{tabular}{ccccc}
\hline \multirow{2}{*}{ KELAS } & \multirow{2}{*}{$\begin{array}{c}\text { JUMLAH } \\
\text { SISWA }\end{array}$} & \multicolumn{3}{c}{ PEMAHAMAN KONSEP } \\
\cline { 3 - 5 } & & $\begin{array}{c}\text { SEBELUM } \\
\text { SIKLUS }\end{array}$ & $\begin{array}{c}\text { SIKLUS } \\
\text { I }\end{array}$ & $\begin{array}{c}\text { SIKLUS } \\
\text { II }\end{array}$ \\
\hline X-1 & 41 & 35 & 44 & 60 \\
X-2 & 40 & 36 & 45 & 64 \\
X-3 & 43 & 33 & 50 & 63 \\
X-4 & 42 & 32 & 49 & 64 \\
X-5 & 41 & 39 & 42 & 61 \\
X-6 & 43 & 33 & 40 & 63 \\
X-7 & 39 & 35 & 46 & 61 \\
X-8 & 40 & 34 & 47 & 62 \\
\hline RATA-RATA (\%) & $\mathbf{3 4 . 6 2 5}$ & $\mathbf{4 5 . 3 7 5}$ & $\mathbf{6 2 . 2 5}$ \\
\hline
\end{tabular}

\section{PERBANDNGGAN PEMAHAMANKONSEP} FISIKA

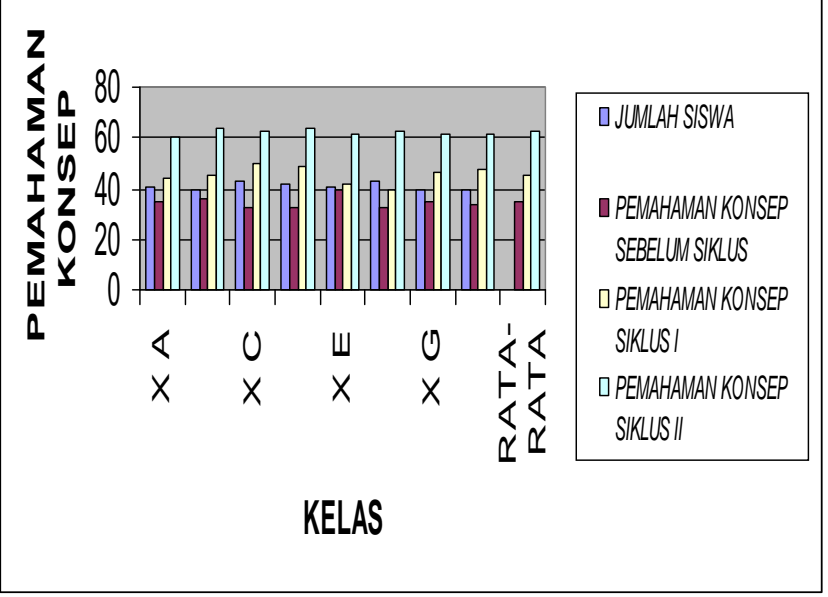

Gambar 1. Perbandingan Pemahaman Konsep 


\section{SANG PENCERAH}

Volume 3, Nomor 2, Agustus 2017, Hlm. 11-18

Arianto Atjo: Meningkatkan Pemahaman Konsep Fisika ...

Tabel 5. Hasil Ketuntasan Belajar

\begin{tabular}{ccccc}
\hline \multirow{2}{*}{ KELAS } & \multirow{2}{*}{ JUMLAH } & \multicolumn{3}{c}{$\begin{array}{c}\text { PERSENTASE KETUNTASAN } \\
\text { BELAJAR }\end{array}$} \\
\cline { 3 - 5 } & \multirow{2}{*}{ SISWA } & $\begin{array}{c}\text { SEBELUM } \\
\text { SIKLUS }\end{array}$ & $\begin{array}{c}\text { SIKLUS } \\
\text { I }\end{array}$ & $\begin{array}{c}\text { SIKLUS } \\
\text { II }\end{array}$ \\
\hline X-1 & 41 & 55 & 64 & 75 \\
X-2 & 40 & 52 & 66 & 78 \\
X-3 & 43 & 53 & 63 & 79 \\
X-4 & 42 & 51 & 62 & 75 \\
X-5 & 41 & 56 & 63 & 74 \\
X-6 & 43 & 55 & 62 & 79 \\
X-7 & 39 & 54 & 65 & 78 \\
X-8 & 40 & 52 & 60 & 77 \\
\hline RATA-RATA (\%) & $\mathbf{5 3 . 5}$ & $\mathbf{6 3 . 1 2 5}$ & $\mathbf{7 6 . 8 7 5}$ \\
\hline
\end{tabular}

\section{HASL KETUNTASANBELAJAR}

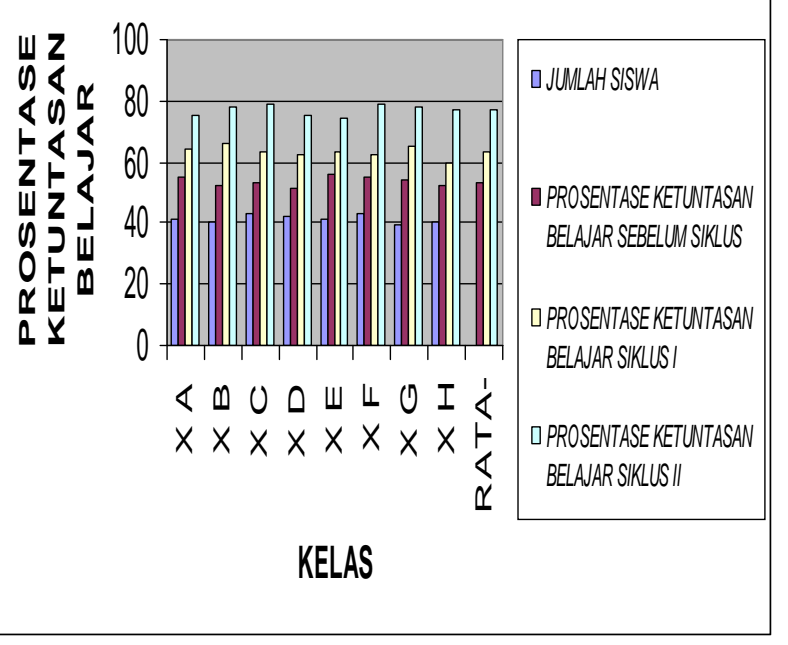

Gambar 2. Hasil Ketuntasan Belajar

Hasil perbaikan tindakan yang dilakukan guru dari siklus I ke siklus II menunjukan ketuntasan hasil belajar fisika siswa meningkat sebesar 13,75\%. Sedangkan kegiatan pada siklus II, bila dibandingkan dibandingkan dengan ketuntasan hasil belajar siswa sebelum pelaksanaan metode demonstrasi, meningkat sebesar 23,38\% (dari 53,5\% menjadi $76,88 \%$ ). Ini menunjukan bahwa pelaksanaan KBM dengan metode demonstrasi yang efektif dan optimal dapat meningkatkan hasil belajar fisika siswa.

\section{Simpulan}

Simpulan penelitian ini bahwa langkah-langkah metode demontrasi yang efektif adalah Pendahuluan: (a) Guru menertipkan suasana kelas; (b) Guru memberikan prasyarat pengetahuan; (c) Guru memberikan motivasi; (d) Guru menyampaikan tujuan pembelajaran; (e) Guru menyiapan alat untuk demonstrasi; $(\mathrm{f})$ Guru menjelaskan kegunaan alat; (g) Guru menjelaskan cara kerja alat; (h) Guru menjelaskan tehnik keselamatan kerja. Kegiatan inti/Pokok: (a) Guru mengukur menggunakan jangka sorong dengan melibatkan siswa; (b) Guru membimbing siswa untuk mencatat hasil pengamatan; (c) Guru memimpin diskusi isian LKS; (d) Guru membimbing siswa untuk kesimpulan. Penutup: (a) Guru melaksanakan evaluasi test lisan atau test tertulis; (b) Guru memberikan contoh dalam kehidupan sehari-hari yang sesuai dengan konsep; (c) Guru meberikan pekerjaan rumah. Hasil belajar fisika siswa meningkat setelah mengikuti kegiatan belajar mengajar yang menggunakan metode demonstrasi. Adapun peningkatan prestasi dari siklus I sampai siklus II sebesar $23,38 \%$.

\section{Daftar Pustaka}

Anonim. 2000. Pedoman Penulisan Karya Ilmiah. 2000. Malang: Uniersitas Negeri Malang.

Budiharti, Rini. 1999. Strategi Belajar Mengajar Bidang Studi. Surakarta : UNS Press. 


\section{SANG PENCERAH}

Volume 3, Nomor 2, Agustus 2017, Hlm. 11-18

\section{Arianto Atjo: Meningkatkan Pemahaman Konsep Fisika ...}

Dasna, I Wayan dan Ach. Fatchan. 2008.

Penelitian Tindakan Kelas dan Karya

Ilmiah, Badan Penyelenggara

Sertifikasi Guru (BPSG). Malang:

Universitas Malang.

Depdikbud, 1994, Kurikulum Sekolah Lanjutan Tingkat Atas, Garis-Garis Besar Program Pengajaran. 1994. Jakarta: Depdikbud.

N.K, Roestiyah. 1998. Strategi Belajar Mengajar. Jakarta: PT Rineka Cipta.

Poerwanto, Ngalim. 1998. Psikologi Pendidikan. Bandung: Remaja Rosdakarya.

Roestiyah N.K. 1989. Strategi Belajar Mengajar. Jakarta: Rineka Cipta

Sardirman A. M. 1990. Interaksi Dan Motivasi Belajar Mengajar. Jakarta: PT Raja Grafindo Persada.

Slameto. 2003. Belajar Dan Faktor-Faktor Yang Mempengaruhinya. Jakarta Rineka Cipta.

Sudijono, Anas. 2005. Evaluasi Pendidikan. Jakarta: PT Raja Grafindo Persada. 
SANG PENCERAH

Volume 3, Nomor 2, Agustus 2017, Hlm. 11-18

Arianto Atjo: Meningkatkan Pemahaman Konsep Fisika ... 